\title{
Long-term outcome in pulmonary arterial hypertension: a plea for earlier parenteral prostacyclin therapy
}

\author{
M. Delcroix, K. Spaas and R. Quarck
}

ABSTRACT: The present review aims to examine the effect of specific drugs on long-term outcome of pulmonary arterial hypertension (PAH), to critically review the available data, and to derive useful information for daily patient care.

$\mathrm{PAH}$ is an intrinsic disease of the pulmonary circulation with a malignant evolution as a consequence of progressive right heart failure. Without specific therapy, median survival is only 2.8 yrs. The intravenous prostacyclin analogue epoprostenol is the only treatment with a demonstrated effect on survival, observed during a single 12-week randomised placebocontrolled trial. Three long-term observational studies have also shown that median survival is raised above 6 yrs with this therapy. Subcutaneous treprostinil appears to have similar beneficial effects on survival, as reported in two long-term observational studies. This is not the case for inhaled iloprost, as shown in one study in which a high proportion of patients needed the addition of, or the switch to, another therapy. Among the oral agents, long-term data have only been published for bosentan. The three studies including patients from expert centres also showed very good survival data, but again with a broad use of combination therapy. In less expert hands, with limited access to more complex therapies, reported survival seems much worse. In these studies, baseline New York Heart Association class and 6-min walk distance are repeatedly shown to be important predictors of survival. Finally, there is emerging data that prostanoid therapy results in a tendency to normalise C-reactive protein levels, a factor associated with improved long-term outcomes.

KEYWORDS: Endothelin receptor antagonists, outcome, prostacyclin analogues, pulmonary arterial hypertension

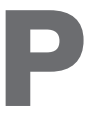

ulmonary arterial hypertension $(\mathrm{PAH})$ is an intrinsic, pre-capillary pulmonary arteriopathy characterised by intima fibrosis, media hypertrophy, matrix proliferation and plexogenic lesions. It includes an idiopathic (IPAH) and a familial/inherited form, as well as pulmonary hypertension associated with connective tissue disease, congenital systemic-to-pulmonary shunts, portal hypertension, HIV and the use of drugs or anorexigens.

In the pre-prostacyclin era, the median survival of untreated patients with IPAH was 2.8 yrs [1], placing IPAH among the most malignant diseases of the middle-aged individual. The 12-week epoprostenol pivotal trial was the first step forward, showing a lower death rate in patients treated with epoprostenol compared with placebo [2]. However, none of the more recent randomised controlled trials have been able to confirm this trend. However, by combining these trials in a metaanalysis involving a total of 3,140 patients, a significant mortality reduction was recently demonstrated [3].

Current PAH-specific therapies target three pathways: the 1) prostacyclin and 2) nitric oxide pathways, with cyclic adenosine monophosphate (cAMP) and cyclic guanosine monophosphate (cGMP) as respective second messengers, both acting as vasodilators and inhibitors of smooth muscle cell proliferation; and 3) the endothelin (ET)-1 pathway, acting via a G protein-coupled receptor as a vasoconstrictor and a proliferating agent. Prostacyclin analogues include epoprostenol, exclusively used intravenously because of its
AFFILIATIONS

Dept of Pneumology, University Hospitals of Leuven, Katholieke Universiteit Leuven, Leuven, Belgium.

CORRESPONDENCE

M. Delcroix

Dept of Pneumology

University Hospital Gasthuisberg

Herestraat 49

3000 Leuven

Belgium

E-mail: marion.delcroix@

uzleuven.be

Received:

May 272009

Accepted after revision:

Aug 102009

PROVENANCE

Submitted article, peer reviewed. 
very short half-life, and more stable compounds, such as treprostinil, which can be used subcutaneously, intravenously, inhaled or orally, iloprost for inhaled and i.v. use, and beraprost for oral use. Inhibitors of cGMP phosphodiesterase 5 , such as sildenafil and the longer-acting tadalafil, are orally administrated and used to increase intracellular concentrations of cGMP. The selective $\mathrm{ET}_{\mathrm{A}^{-}}$(sitaxsentan and ambrisentan) and dual $\mathrm{ET}_{\mathrm{A}^{-}}$and $\mathrm{ET}_{\mathrm{B}}$-receptor (bosentan) antagonists have been developed for oral use.

The regulatory approval and subsequent clinical use of these agents is based on trials of between 12 and 16 weeks' duration demonstrating improvements in exercise capacity. The present review discusses current evidence exceeding this time interval. Given the paucity of randomised trials, conclusions are more difficult. We ask, therefore, do we really improve long-term survival in PAH? And, if so, what may be the optimal strategy?

\section{LONG-TERM PLACEBO-CONTROLLED STUDIES}

The only published long-term, placebo-controlled study in $\mathrm{PAH}$ is the American beraprost study [4]. It was a 1-yr, multicentre, double-blind, randomised, placebo-controlled trial, which included $116 \mathrm{PAH}$ patients and looked at disease progression, 6-min walk distance (6MWD), peak oxygen consumption, Borg dyspnoea score, haemodynamics, symptoms and quality of life. Baseline characteristics of the study population were a mean age of $42 \pm 2$ yrs, a 6 MWD of $439 \pm 11 \mathrm{~m}$ and a New York Heart Association (NYHA) functional class II to III repartition of 52.5 to $47.5 \%$. Beraprost was administrated four times daily at an increasing mean dose of $71 \mu \mathrm{g}$ at 3 months, $92 \mu \mathrm{g}$ at 6 months and $107 \mu \mathrm{g}$ at 12 months. In this study, the initial improvement in exercise capacity was no longer significant at $1 \mathrm{yr}$. The beraprost-treated patients had improved 6MWD by $22 \mathrm{~m}$ from baseline at 3 months $(p=0.010)$ and by $31 \mathrm{~m}$ at 6 months $(\mathrm{p}=0.016)$ compared with placebo, but not at 9 or 12 months. There was also no effect on haemodynamics at 12 months.

Beside this, some medium-term data for bosentan-treated patients exists. A 48 patient subset of the BREATHE-1
(Bosentan Randomized Trial of Endothelin Antagonist Therapy) 16-week pivotal trial [5] entered a second blinded period of 12 weeks. In the 35 patients who continued bosentan blinded treatment, there was a slight decrease in 6MWD at 28 weeks that, even if it was not significant, was somewhat worrisome (unpublished data).

Instead of increasing placebo-controlled study duration, randomised withdrawal is another way to show durability of drug effect. This approach, somewhat controversial for a lifesustaining therapy, has been cautiously used for epoprostenol, showing that down-titration after a mean of 3.4 yrs of treatment was uniformly accompanied by clinical deterioration [6].

\section{OBSERVATIONAL STUDIES}

To compensate for the scarcity of long-term controlled data on drug efficacy in PAH, large observational studies have been proposed in order to evaluate long-term outcome. These studies are presently available for most of the specific PAH medications (epoprostenol, treprostinil, iloprost and bosentan). However, we have to be aware of the numerous limitations of these studies: they were open-label studies, and there were patient drop-outs, treatment changes and an absence of contemporary control groups.

Focusing on long-term data with i.v. epoprostenol, we identified three major studies (table 1). The first, by BARST et al. [7], is an open-label follow-up of 18 patients previously included in the initial randomised controlled trial from RUBIN et al. [10]. The second, by SitBon et al. [8], and the third, by MCLAUGHLin et al. [9], are much larger single-centre series of patients, from the French and US reference centres in Clamart and Chicago, IL, respectively. In the studies by BARST et al. [7] and SITBON et al. [8], survival of epoprostenol-treated patients was compared to a matched historical cohort, while in the study by MCLAUGHLIN et al. [9] survival was predicted from the d'Alonzo equation, derived from the US National Institutes of Health (NIH) registry population [1]. This equation has been largely used to calculate survival on the basis of haemodynamic parameters (mean

TABLE 1 Long-term response to intravenous epoprostenol

\begin{tabular}{|c|c|c|c|}
\hline & BARST [7] & SitBon [8] & McLAUGHLIN [9] \\
\hline Drug & Epoprostenol & Epoprostenol & Epoprostenol \\
\hline Patients & 18 IPAH & 178 IPAH & 162 IPAH \\
\hline End-points & 6MWD, haemodynamics, death & NYHA, 6MWD, PVR, death & NYHA, haemodynamics, death \\
\hline NYHA FC II/III-V \% & $6 / 94$ & $0 / 100$ & $0 / 100$ \\
\hline \multirow[t]{3}{*}{ Dose $\mathbf{n g} \cdot \mathrm{kg}^{-1} \cdot \mathrm{min}^{-1}$} & 1 yr: $18 \pm 11$ & 3 months: $14 \pm 4$ & 17 months: $35 \pm 30$ \\
\hline & 2 yrs: $37 \pm 21$ & $1 \mathrm{yr}: 21 \pm 7$ & 30 months: $52 \pm 35$ \\
\hline & 3 yrs: $53 \pm 30$ & 41 months: $33 \pm 11$ & 43 months: $55 \pm 42$ \\
\hline Age yrs & $36 \pm 13$ & $43 \pm 13$ & 42 \\
\hline
\end{tabular}

Data are presented as mean \pm SD unless otherwise stated. Cl: cardiac index; 6MWD: 6-min walk distance; NYHA: New York Heart Association; FC: functional class; NIH: National Institutes of Health; IPAH: idiopathic pulmonary arterial hypertension; PVR: pulmonary vascular resistance. 
TABLE 2 Long-term survival in pulmonary arterial hypertension (PAH)

\begin{tabular}{|c|c|c|c|c|c|c|c|c|c|c|c|}
\hline & \multirow[t]{2}{*}{ Drug } & \multirow[t]{2}{*}{ Patients $\mathrm{n}$} & \multirow[t]{2}{*}{ Type } & \multirow[t]{2}{*}{$\mathrm{CI} \mathrm{L} \cdot \mathrm{min}^{-1} \cdot \mathrm{m}^{-2}$} & \multirow[t]{2}{*}{ NYHA } & \multirow[t]{2}{*}{ 6MWD m } & \multirow[t]{2}{*}{ OA \% } & \multicolumn{3}{|c|}{ Survival \% } & \multirow[t]{2}{*}{ Comb. \% } \\
\hline & & & & & & & & $1 \mathrm{yr}$ & $2 \mathrm{yrs}$ & $3 \mathrm{yrs}$ & \\
\hline JING [11] & Conservative treatment & 72 & IPAH & & $2.76 \pm 0.7$ & & 50 & 68 & 57 & 39 & \\
\hline Christie [12] & Lung transplant & 970 & IPAH & & & & & 67 & 61 & 57 & \\
\hline McLaughLin [9] & Epoprostenol & 162 & IPAH & $1.82 \pm 0.57$ & $3.54 \pm 0.5$ & & & 88 & 76 & 63 & \\
\hline BARST [13] & Treprostinil & 860 & $\mathrm{PAH}$ & & $2.94 \pm 0.5$ & & & 87 & 78 & 71 & 15 \\
\hline LANG $[14]$ & Treprostinil & 122 & $\mathrm{PAH} / \mathrm{CTEPH}$ & $2.13 \pm 0.66$ & $3.20 \pm 0.04$ & $305 \pm 11$ & 95 & 89 & & 71 & 18 \\
\hline OPITZ [15] & Inhaled iloprost & 76 & IPAH & $1.80 \pm 0.81$ & $2.86 \pm 0.6$ & & 47 & 79 & 70 & 59 & 54 \\
\hline HoEPER [16] & i.v. iloprost & 79 & $\mathrm{PAH}$ & $1.70 \pm 0.60$ & $3.23 \pm 0.4$ & $287 \pm 112$ & & 86 & 73 & 59 & \\
\hline McLAUGHLIN [17] & Bosentan & 169 & IPAH & $2.35 \pm 0.80$ & $2.99 \pm 0.5$ & $345 \pm 87$ & & 96 & 89 & 86 & 30 \\
\hline SItBon [22] & Calcium channel blockers & 38 & IPAH (LTR) & & $2.34 \pm 1.0$ & $380 \pm 112$ & & 97 & 97 & 97 & \\
\hline
\end{tabular}

Data are presented as mean $\pm \mathrm{SD}$, unless otherwise stated. Summary of large cohorts treated with epoprostenol, treprostinil, iloprost and bosentan in comparison with conservative treatment, lung transplantation, atrial septostomy and calcium channel blockers. Cl: cardiac index; NYHA: New York Heart Association; 6MWD: 6-min walk distance; OA: proportion of patients treated with oral anticoagulants; Comb.: proportion of patients started with combination or switched from therapy during the observation period; IPAH: idiopathic PAH; CTEPH: chronic thromboembolic pulmonary hypertension; R: responders; LTR: long-term responders.

pulmonary arterial pressure, cardiac index and right atrial pressure). These three studies included IPAH patients with severe disease, as evidenced by their poor cardiac index $<2 \mathrm{~L} \cdot \mathrm{min}^{-1} \cdot \mathrm{m}^{-2}$, poor baseline 6MWD of $\sim 250 \mathrm{~m}$ and the almost exclusive NYHA class III and IV inclusion. As a consequence of the well-known tolerance to prostanoid, epoprostenol dose was progressively increased to $30 \mathrm{ng} \cdot \mathrm{kg}^{-1} \cdot \mathrm{min}^{-1}$ at $3 \mathrm{yrs}$ in the French cohort and $50 \mathrm{ng} \cdot \mathrm{kg}^{-1} \cdot \mathrm{min}^{-1}$ in the US series. Survival data at 1, 2 and 3 yrs are reported in table 2. BARST et al. [7] reported a significant survival improvement in epoprostenol-treated patients when compared with the historical control group $(p=0.045)$, and the median survival reached more than 6 yrs. These results were confirmed in the SITBON et al. [8] and MCLAUGHLIN et al. [9] series, in which survival was similar despite the substantial differences in dosage. Both studies also confirmed the importance of the baseline NYHA functional class in predicting the outcome of epoprostenol-treated IPAH patients, as originally shown in the NIH registry untreated population [1]. However, despite the poorer prognosis, median survival in class IV patients was prolonged from 6 months to $>3$ yrs in both cohorts.

More recently, two retrospective studies using subcutaneous treprostinil in patients with PAH have been published (table 3). The first, by LANG et al. [14], described 122 patients, including 99 with PAH and 23 with chronic thromboembolic pulmonary hypertension, started with treprostinil in three European centres. The second, by BARST et al. [13], assessed $860 \mathrm{PAH}$ patients, including patients previously enrolled in the pivotal trials as well as de novo patients from the USA. At baseline, patients had less severe disease than those of the epoprostenol series, as demonstrated by their baseline 6MWD of $\sim 300 \mathrm{~m}$ and cardiac index
$>2 \mathrm{~L} \cdot \mathrm{min}^{-1} \cdot \mathrm{m}^{-2}$, the predominance of NYHA class III patients and the inclusion of some class II patients. Within $3 \mathrm{yrs}$, the treprostinil dose was progressively increased to $40 \mathrm{ng} \cdot \mathrm{kg}^{-1} \cdot \mathrm{min}^{-1}$ in both the European and the predominantly US cohorts. Survival data at 1, 2 and 3 yrs are reported in table 2. LANG et al. [14] reported a $65-\mathrm{m}$ increase in $6 \mathrm{MWD}$ and an improvement in NYHA class at $1 \mathrm{yr}$, both of which were maintained at 2 and 3 yrs. This contrasts with the modest improvements seen in the pivotal 12-week study [23], in which the median placebocorrected increase in 6MWD was only $16 \mathrm{~m}$, reflecting the significant dosing limitations which resulted from local infusion pain. In addition, survival among the $32 \mathrm{IPAH}$ patients was significantly better than predicted and comparable with the survival obtained with i.v. epoprostenol. The favourable longterm data were confirmed in the 332 IPAH patients of the study by BARST et al. [13], showing that survival of patients receiving treprostinil in monotherapy was not different from that of the entire cohort. Oral therapy, predominantly bosentan, but also sildenafil, was added in $18 \%$ and $15 \%$ of the LANG et al. [14] and BARST et al. [13] studies, respectively. Drop-out due to infusion site pain was observed in 5\% of the patients included in the LANG et al. [14] study and in $23 \%$ of the patients included in the larger cohort studied by BARST et al. [13], highlighting the importance of dedicated centres for efficient patient support. BARST et al. [13] also confirmed the predictive value of baseline NYHA functional class, as well as baseline $6 \mathrm{MWD}$, pulmonary vascular resistance and mixed venous oxygen saturation, in the outcome of treprostinil-treated PAH patients. Having a baseline NYHA class $\mathrm{IV}$, a $6 \mathrm{MWD}<295 \mathrm{~m}$, an indexed pulmonary vascular resistance $>30 \mathrm{WU} \cdot \mathrm{m}^{-2}$, or a mixed venous oxygen saturation $<55 \%$, was associated with a $52-59 \%$ risk of dying within 3 yrs [24]. 
TABLE 3 Long-term response to subcutaneous treprostinil

\begin{tabular}{|c|c|c|}
\hline & LANG [14] & BARST [13] \\
\hline Drug & Treprostinil & Treprostinil \\
\hline Patients & $99 \mathrm{PAH}, 23$ СТЕРН & $860 \mathrm{PAH}$ \\
\hline End-points & 6MWD, NYHA FC, survival, event-free survival & Survival, survival on monotherapy \\
\hline NYHA FC II/III/IV \% & $7 / 66 / 27$ & $15 / 76 / 9$ \\
\hline \multirow[t]{4}{*}{ Dose $\mathrm{ng} \cdot \mathrm{kg}^{-1} \cdot \mathrm{min}^{-1}$} & 1 yr: 26 & 1 yr: 26 \\
\hline & 2 yrs: 32 & 2 yrs: 36 \\
\hline & 3 yrs: 40 & 3 yrs: 42 \\
\hline & & 4 yrs: 42 \\
\hline Age yrs & $49(12-81)$ & $46(5-84)$ \\
\hline
\end{tabular}

Data are presented as mean \pm SD or mean (range), unless otherwise stated. Cl: cardiac index; 6MWD: 6-min walk distance; NYHA: New York Heart Association; FC: functional class; PAH: pulmonary arterial hypertension; CTEPH: chronic thromboembolic pulmonary hypertension.

Evidence for the use of the prostacyclin-analogue iloprost is reliant upon two long-term studies: one by OPITZ et al. [15], performed with inhaled administration and one by HOEPER et al. [16] with i.v. administration. In most cases, i.v. administration became a second-line therapy for patients initially treated with inhaled iloprost for a median of 12 months (table 4). Whereas baseline 6MWD was not available in the cohort studied by OPITZ et al. [15], most of the patients included were in NYHA class II and III. Iloprost $(100 \mu \mathrm{g})$ was administered as six inhalations per day. In the cohort studied by HOEPER et al. [16], patients were severely sick at the start of i.v. iloprost therapy, with a baseline $6 \mathrm{MWD}$ of $228 \mathrm{~m}$, a cardiac index $<2 \mathrm{~L} \cdot \mathrm{min}^{-1} \cdot \mathrm{m}^{-2}$ and a majority in NYHA class IV. Iloprost dose was increased to $2.6 \mathrm{ng} \cdot \mathrm{kg}^{-1} \cdot \mathrm{min}^{-1}$ at 6 months. Survival data at 1, 2 and 3 yrs are reported in table 2 . In the study by OpITz et al. [15], only $20 \%$ of the patients were still on iloprost monotherapy at 3 yrs. In the study by HOEPER et al. [16], median survival was only 3 yrs from diagnosis and 1 year from i.v. iloprost initiation, which does not differ from survival without specific treatment [1]. However, this study included a selection of patients with a mean pulmonary vascular resistance $>1,500 \mathrm{dyn} \cdot \mathrm{s} \cdot \mathrm{cm}^{-5}$, who were doing poorly on inhaled iloprost, and who were probably underdosed with i.v. iloprost (dosage used in UK centres is about 3.3 and $4.7 \mathrm{ng} \cdot \mathrm{kg}^{-1} \cdot \mathrm{min}^{-1}$ at 3 and 12 months, respectively).

TABLE 4 Long-term response to inhaled and intravenous iloprost

\section{OPITZ [15]}

Inhaled iloprost

5-yr, multicentre, prospective analysis

76 IPAH

Survival, event-free survival (death, lung transplant, i.v. therapy, start oral agents)

$$
1.8 \pm 0.81
$$

Baseline 6MWD m

NYHA FC II/III/IV \%

Mean dose

Age yrs
$24 / 67 / 9$

$100 \mu \mathrm{g} \cdot \mathrm{day}^{-1}$

in six inhalations (nebuliser) $43 \pm 0.1$

\section{HOEPER [16]}

\section{i.v. iloprost}

6-yr, multicentre, retrospective, second-line of inhaled iloprost (95\%, 12 months)

$79 \mathrm{PAH}$

Survival, lung transplant-free survival

$$
\begin{gathered}
\text { Diagnosis: } 1.7 \pm 0.6 \\
\text { Onset i.v. iloprost: } 1.5 \pm 0.4 \\
\text { Diagnosis: } 287 \pm 112 \\
\text { Onset i.v. iloprost: } 228 \pm 114 \\
\text { Diagnosis: } 0 / 77 / 23 \\
\text { Onset } i . v \text {. iloprost: } 0 / 33 / 67 \\
1.8 \mathrm{ng} \cdot \mathrm{kg}^{-1} \cdot \mathrm{min}^{-1} \text { at discharge } \\
2.6 \mathrm{ng} \cdot \mathrm{kg}^{-1} \cdot \mathrm{min}^{-1} \text { at } 6 \text { months } \\
47 \pm 13
\end{gathered}
$$

Data are presented as mean \pm SD, unless otherwise stated. Cl: cardiac index; 6MWD: 6-min walk distance; NYHA: New York Heart Association; FC: functional class; PAH: pulmonary arterial hypertension; IPAH: idiopathic PAH. 


\section{TABLE 5 Long-term response to oral bosentan}

\begin{tabular}{|c|c|c|c|}
\hline Drug & Bosentan & Bosentan & Bosentan \\
\hline Patients & $169 \mathrm{IPAH}$ & $123 \mathrm{PAH}$ & $103 \mathrm{IPAH}$ \\
\hline End-points & Survival & $\begin{array}{l}\text { Survival, lung transplant-free and i.v. } \\
\text { prostanoid-free survival }\end{array}$ & Survival \\
\hline Baseline 6MWD m & $345 \pm 87$ & $308 \pm 133$ & $319 \pm 105$ \\
\hline NYHA FC II/III/IV \% & $9 / 82 / 9$ & $0 / 80 / 20$ & 0/88/12 \\
\hline Dose & $2 \times 125 \mathrm{mg}$ & $2 \times 125 \mathrm{mg}$ & $2 \times 125 \mathrm{mg}$ \\
\hline Age yrs & $46 \pm 16$ & $52 \pm 14$ & $54 \pm 16$ \\
\hline
\end{tabular}

Data are presented as mean \pm SD, unless otherwise stated. CI: cardiac index; 6MWD: 6-min walk distance; NYHA: New York Heart Association; FC: functional class; PAH: pulmonary arterial hypertension; IPAH: idiopathic PAH.

Nevertheless, this study confirmed the importance of baseline $6 \mathrm{MWD}$ and mixed venous oxygen saturation in predicting the outcome of iloprost-treated patients with PAH.

Concerning oral agents, long-term data are only available for the dual receptor antagonist bosentan (table 5). Three series have been published: the one studied by MCLAUGHLIN et al. [17] is an open-label follow-up of patients included in two randomised controlled trials [5, 25]; those published by HOEPER et al. [18] and PROVENCHER et al. [19] are single-centre series from Germany and France, respectively. The McLAughlin et al. [17] and PROVENCHER et al. [19] studies only included IPAH patients. Patients were less sick than in the prostanoid studies, with baseline 6MWD 300-350 m, and predominantly in NYHA class III. They received the recommended dose of bosentan $(125 \mathrm{mg}$ b.d.). Survival data at 1, 2 and 3 yrs are reported in table 2 . MCLAUGHLIN et al. [17] reported survival that was better than predicted estimates, with a mortality of $5.5 \%$ per annum. However, $30 \%$ of the patients were on combined therapy at 3 yrs. Similarly good survival data were confirmed in the two other cohorts. The goal-oriented approach adopted by HOEPER et al. [18], with additional drugs added every 2 to 6 months if predefined goals were not attained (6MWD $>380 \mathrm{~m}$, peak oxygen uptake $>10.4 \mathrm{~mL} \cdot \mathrm{min}^{-1} \cdot \mathrm{kg}^{-1}$ and peak systolic blood pressure $>120 \mathrm{mmHg}$ ), did not provide a survival advantage when compared to the other two series. However, in the cohort studied by PROVENCHER et al. [19] only $40 \%$ of the patients remained on bosentan monotherapy at 3 yrs, a prostanoid being added in patients with NYHA class $>$ II, 6MWD $<250 \mathrm{~m}$ and cardiac index $<2.2 \mathrm{~L} \cdot \mathrm{min}^{-1} \cdot \mathrm{m}^{-2}$. Only $3 \%$ of the patients stopped bosentan because of elevated liver enzymes in this cohort.

\section{COMPARISON OF THE DIFFERENT THERAPEUTIC APPROACHES}

Since no direct comparison between PAH-specific medications has been performed, it is interesting to place in perspective the survival data collected from the aforementioned long-term observational studies (table 2). The first two rows display series performed when no PAH-specific therapy was available in the USA [1] and in China [11]. It should be emphasised that the historical data obtained by D'AlONZO et al. [1], frequently contested as a comparator, were reaffirmed by more recent survival data from China where PAH-specific therapies are not widely available. The third row displays the most recent survival data concerning lung transplantation in PAH reported by the International Society of Heart and Lung Transplantation [12].

Concerning the survival benefit raised by the PAH specific therapies, it is notable that different series across different countries or continents provided remarkably similar survival data within each drug category: $63 \%$ at 3 yrs for epoprostenol, $71 \%$ for treprostinil, 59\% for iloprost and $80 \%$ for bosentan (table 2). It is also important to note that: 1) these positive survival data were actually obtained with broad use of combination therapies, especially concerning bosentan studies; 2) in comparison with the NIH historical group of patients, anticoagulants were used in a larger extent in the most recent series; and 3) less sick patients were included in the bosentan series, as demonstrated by the cardiac index, NYHA class and the $6 \mathrm{MWD}$. This evolution precludes the comparison of oral agent and parenteral prostanoid efficacy, although it is obvious that more patients are surviving on monotherapy with parenteral prostanoids $(85 \%)$ then with oral agents $(55 \%)$.

Despite being acceptable when compared with historical controls, survival rates with PAH-specific drugs seem inferior when those patients with severe symptoms are compared with results after atrial septostomy [20]. However, these data need to be confirmed by other studies. Moreover, the small group of patients with reversible IPAH $(\sim 7 \%)$ who are long-term responders to calcium channel blockers seem to have a favourable prognosis, with survival $>87 \%$ at 3 yrs $[21,22]$ without the need for additional, more specific, agents.

\section{REAL-LIFE EXPERIENCE WITH PAH THERAPIES}

Beside these optimistic data, another perspective on current therapeutic practices in $\mathrm{PAH}$ has been provided by Accredo, a company which delivers different PAH-specific drugs to US patients. They reported, at the 2008 congress of the Pulmonary Hypertension Association, that an elevated proportion of patients who were dying from $\mathrm{PAH}$ were on oral agent monotherapy [26]. In a series of 821 patients, who were 

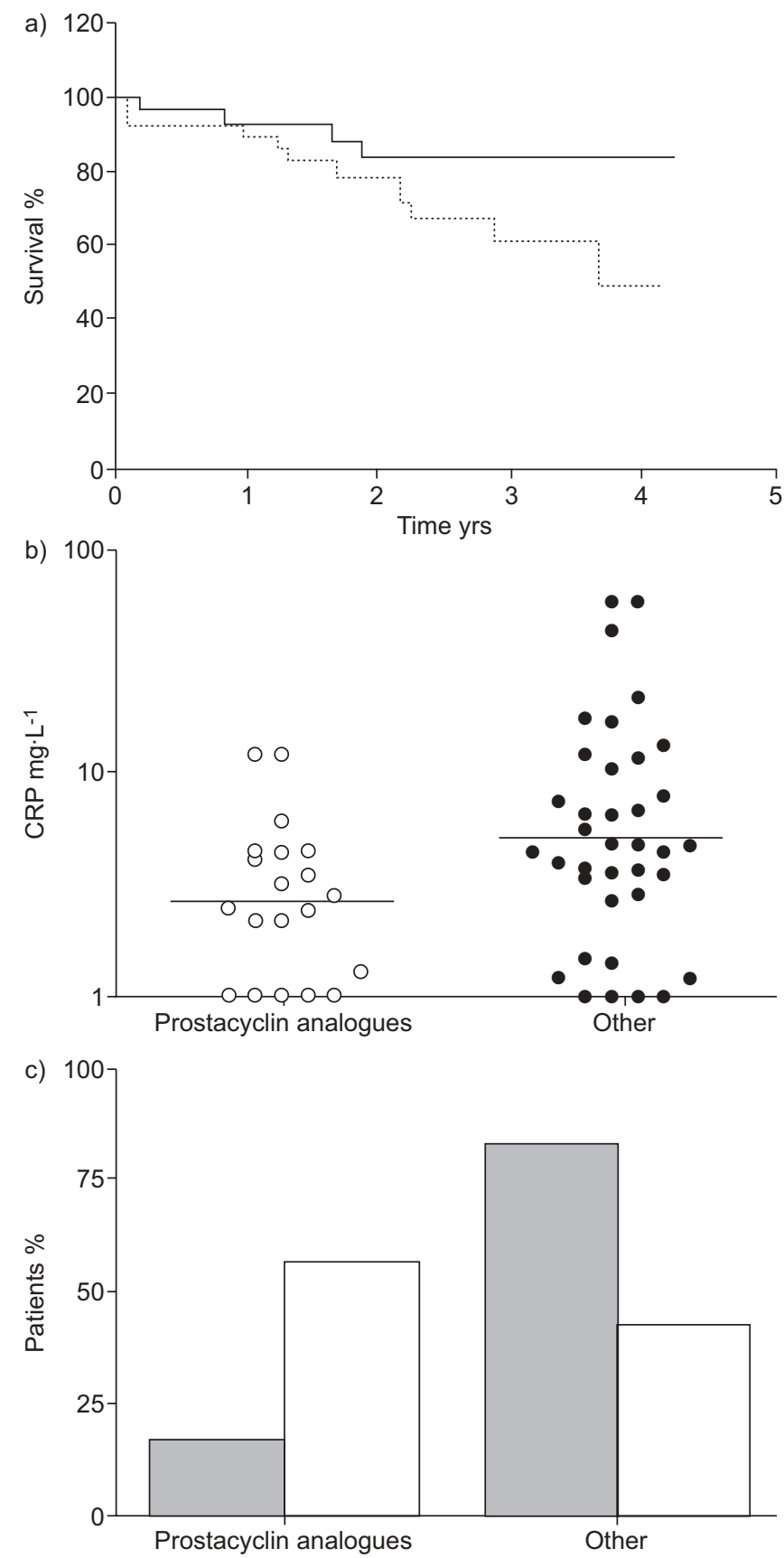

FIGURE 1. Effect of pulmonary arterial hypertension-specific treatment on systemic inflammation. a) Kaplan-Meyer survival curves for patients normalising their $\mathrm{C}$-reactive protein (CRP) levels under treatment (responders, i.e. CRP $\leqslant 5 \mathrm{mg} \cdot \mathrm{L}^{-1} ; \longrightarrow$ ) versus nonresponders (i.e. CRP $\left.\geqslant 5 \mathrm{mg} \cdot \mathrm{L}^{-1} ; \cdots \cdots \cdot\right)(\mathrm{p}<0.05)$. b) CRP levels in patients treated with prostacyclin analogues versus patients treated with another drug $(p=0.01)$. — : geometric means. c) Proportion of patients treated with prostacyclin analogues versus another drug among the responders $(\square)$ and nonresponders $(\square)(p=0.002)$. Reproduced from [28] with permission from the publisher.

initiated on bosentan between October 1 and December 31, 2004 , overall survival at 3 yrs was only $64 \%$, in comparison with the previously reported $80 \%$ by the German and French expert centres [18, 19]. From the 190 patients who died, 169
$(89 \%)$ were on bosentan monotherapy, and only $11 \%$ were treated with prostanoids before death. The vast majority of them had never been referred to an expert centre.

The good survival data of patients treated with bosentan in expert centres were obtained with a broad and undelayed use of combination therapy including a prostanoid [18, 19]. In less experienced hands, with limited access to combined therapies, reported survival appears severely impaired.

\section{ANTI-INFLAMMATORY EFFECTS OF PAH DRUGS AND LONG-TERM SURVIVAL}

Another appealing observation is the effect of prostanoids on systemic inflammation. Prostacyclin analogues interact in different ways with inflammatory cells [27]. However, the relevance of this for the treatment of pulmonary hypertension remained unknown until the following findings were reported: 1) circulating $\mathrm{C}$-reactive protein (CRP) levels are increased in PAH patients and are significantly higher in NYHA class IIIIV patients and in nonsurvivors; 2) patients with CRP levels $>5.0 \mathrm{mg} \cdot \mathrm{L}^{-1}$ have a significantly lower survival rate and CRP is an independent predictor of survival; and 3) patients normalising their CRP levels under treatment, assigned as responders, have a significantly higher survival rate (fig. 1a) [28]. It is noteworthy that the proportion of patients treated with a prostacyclin analogue was significantly higher among the responders (55\% versus 17\%; fig. $1 \mathrm{~b}$ ). Patients undergoing prostanoid therapy also displayed significantly lower CRP levels (fig. 1c).

Since inflammation appears to play a role among the pathological mechanisms of PAH [29], the anti-inflammatory properties of prostanoids, illustrated by a tendency to normalise CRP, may be a relevant finding.

\section{CONCLUSION}

In conclusion, there is a large body of very consistent evidence for improved survival from long-term observational studies performed in different centres and countries, accompanied by a sustained benefit in 6MWD and NYHA functional class. The latest series on oral therapy included patients with less severe disease and more stable prevalent cases, which artificially contributed to improved survival. Additionally, it seems that: 1) more patients are surviving on monotherapy with parenteral prostanoids than with oral agents; 2) a large proportion of patients who are dying are on monotherapy with oral agents and not treated in reference centres with access to all therapies; and 3) prostanoids seem to have a more pronounced antiinflammatory effect, with implications for the prognosis.

This emphasises the need to escalate treatment rapidly, to promote treatment strategies including prostanoid use, and to accelerate transfer to reference centres.

\section{STATEMENT OF INTEREST}

M. Delcroix has been on advisory boards for Actelion, GSK and Pfizer, has received speaker fees from Actelion, Encysive and LungRx, and research grants from Actelion, Encysive and GSK.

\section{ACKNOWLEDGEMENTS}

The authors thank A. La Gerche (University Hospitals of Leuven, Katholieke Universiteit Leuven, Leuven, Belgium) for valuable editorial comments. 


\section{REFERENCES}

1 D'Alonzo G, Barst RJ, Ayres SM, et al. Survival in patients with primary pulmonary hypertension. Ann Intern Med 1991; 115: 343-349.

2 Barst RJ, Rubin LJ, Long WA, et al. A comparison of continuous intravenous epoprostenol (prostacyclin) with conventional therapy for primary pulmonary hypertension. The Primary Pulmonary Hypertension Study Group. N Engl J Med 1996; 334: 296-302.

3 Galie N, Manes A, Negro L, et al. A meta-analysis of randomized controlled trials in pulmonary arterial hypertension. Eur Heart J 2009; 30: 394-403.

4 Barst RJ, McGoon M, McLaughlin V, et al. Beraprost therapy for pulmonary arterial hypertension. J Am Coll Cardiol 2003; 41: 21192125.

5 Rubin LJ, Badesch DB, Barst RJ, et al. Bosentan therapy for pulmonary arterial hypertension. N Engl J Med 2002; 346: 896-903.

6 Rubenfire M, McLaughlin VV, Allen RP, et al. Transition from IV epoprostenol to subcutaneous treprostinil in pulmonary arterial hypertension: a controlled trial. Chest 2007; 132: 757-763.

7 Barst RJ, Rubin LJ, McGoon MD, et al. Survival in primary pulmonary hypertension with long-term continuous intravenous prostacyclin. Ann Intern Med 1994; 121: 409-415.

8 Sitbon $\mathrm{O}$, Humbert $\mathrm{M}$, Nunes $\mathrm{H}$, et al. Long-term intravenous epoprostenol infusion in primary pulmonary hypertension: prognostic factors and survival. J Am Coll Cardiol 2002; 40: 780-788.

9 McLaughlin VV, Shillington A, Rich S. Survival in primary pulmonary hypertension: the impact of epoprostenol therapy. Circulation 2002; 106: 1477-1482.

10 Rubin LJ, Mendoza J, Hood M, et al. Treatment of primary pulmonary hypertension with continuous intravenous prostacyclin (epoprostenol). Results of a randomized trial. Ann Intern Med 1990; 112: 485-491.

11 Jing $Z C, X u X Q$, Han $Z Y$, et al. Registry and survival study in Chinese patients with idiopathic and familial pulmonary arterial hypertension. Chest 2007; 132: 373-379.

12 Christie JD, Edwards LB, Aurora P, et al. Registry of the International Society for Heart and Lung Transplantation: twentyfifth official adult lung and heart/lung transplantation report 2008. J Heart Lung Transplant 2008; 27: 957-969.

13 Barst RJ, Galie N, Naeije R, et al. Long-term outcome in pulmonary arterial hypertension patients treated with subcutaneous treprostinil. Eur Respir J 2006; 28: 1195-1203.

14 Lang I, Gomez-Sanchez M, Kneussl M, et al. Efficacy of long-term subcutaneous treprostinil sodium therapy in pulmonary hypertension. Chest 2006; 129: 1636-1643.

15 Opitz CF, Wensel R, Winkler J, et al. Clinical efficacy and survival with first-line inhaled iloprost therapy in patients with idiopathic pulmonary arterial hypertension. Eur Heart J 2005; 26: 1895-1902.
16 Hoeper MM, Gall H, Seyfarth HJ, et al. Long-term outcome with intravenous iloprost in pulmonary arterial hypertension. Eur Respir J 2009; 34: 132-137.

17 McLaughlin VV, Sitbon O, Badesch DB, et al. Survival with firstline bosentan in patients with primary pulmonary hypertension. Eur Respir J 2005; 25: 244-249.

18 Hoeper MM, Markevych I, Spiekerkoetter E, et al. Goal-oriented treatment and combination therapy for pulmonary arterial hypertension. Eur Respir J 2005; 26: 858-863.

19 Provencher S, Sitbon O, Humbert M, et al. Long-term outcome with first-line bosentan therapy in idiopathic pulmonary arterial hypertension. Eur Heart J 2006; 27: 589-595.

20 Sandoval J, Gaspar J, Pulido T, et al. Graded balloon dilation atrial septostomy in severe primary pulmonary hypertension. A therapeutic alternative for patients nonresponsive to vasodilator treatment. J Am Coll Cardiol 1998; 32: 297-304.

21 Rich S, Kaufmann E, Levy PS. The effects of high doses of calciumchannel blockers on survival in primary pulmonary hypertension. N Engl J Med 1992; 327: 76-81.

22 Sitbon $\mathrm{O}$, Humbert M, Jais X, et al. Long-term response to calcium channel blockers in idiopathic pulmonary arterial hypertension. Circulation 2005; 111: 3105-3111.

23 Simonneau G, Barst RJ, Galie N, et al. Continuous subcutaneous infusion of treprostinil, a prostacyclin analogue, in patients with pulmonary arterial hypertension: a double-blind, randomized, placebo-controlled trial. Am J Respir Crit Care Med 2002; 165: 800-804

24 Arneson C. Prognostic Factors Associated with Survival in $860 \mathrm{PAH}$ Patients Treated With Subcutaneous Treprostinil Over a 3 Year Period. Pulmonary Hypertension Association Congress, 2008. www. phassociation.org/Medical/articles/SS2008/1045-Arneson,Carl.pdf Date last updated: June 22, 2008. Date last accessed: May 27, 2009.

25 Channick R, Badesch DB, Tapson VF, et al. Effects of the dual endothelin receptor antagonist bosentan in patients with pulmonary hypertension: a placebo-controlled study. J Heart Lung Transplant 2001; 20: 262-263.

26 Tankersley MA, D'Albini LD, Ozanich AN, et al. A 36-month Survival Analysis of Patients Beginning Oral PAH Monotherapy: An Indication for Escalation of Therapy? Pulmonary Hypertension Association Congress, 2008. www.phassociation.org/Medical/ articles/SS2008/1062-Tankersley,Mark.pdf Date last updated: June 22, 2008. Date last accessed: May 27, 2009.

27 Olschewski H, Olschewski A, Rose F, et al. Physiologic basis for the treatment of pulmonary hypertension. J Lab Clin Med 2001; 138 287-297.

28 Quarck R, Nawrot T, Meyns B, et al. C-reactive protein: a new predictor of adverse outcome in pulmonary arterial hypertension J Am Coll Cardiol 2009; 53: 1211-1218.

29 Dorfmuller P, Perros F, Balabanian K, et al. Inflammation in pulmonary arterial hypertension. Eur Respir J 2003; 22: 358-363. 